\title{
REVIEW
}

\section{Drug eluting stents: are human and animal studies comparable?}

\section{R Virmani, F D Kolodgie, A Farb, A Lafont}

Animal models of stenting probably predict human responses as the stages of healing are remarkably similar. What is characteristically different is the temporal response to healing, which is substantially prolonged in humans. The prevention of restenosis in recent clinical trials of drug eluting stents may represent a near absent or incomplete phase of intimal healing. Continued long term follow up of patients with drug eluting stents for major adverse cardiac events and angiographic restenosis is therefore imperative.

See end of article for authors' affiliations

.......

Correspondence to: Dr Renu Virmani, Department of

Cardiovascular Pathology, Armed Forces Institute of Pathology, 6825 16th Street NW, Washington DC 20306-6000, USA: virmani@afip.osd.mil

Accepted 22 September 2002
O ver recent decades, percutaneous interventions have emerged as the preferred treatment for coronary artery disease. In the USA alone, more than one million percutaneous interventions are undertaken annually and more than $80 \%$ involve the use of coronary stents. ${ }^{1}$ Although coronary stenting has had a dramatic impact on restenosis rates, restenosis still occurs in up to $30 \%$ of cases. ${ }^{2}$ Moreover, the treatment of in-stent restenosis is a greater technical challenge than restenosis following balloon angioplasty alone, and often leads to additional catheter based or surgical revascularisation attempts. Drug eluting stents have emerged recently as promising agents in the prevention and treatment of stent related restenoses. Both sirolimus eluting and paclitaxel eluting stents represent an exciting breakthrough treatment, with remarkably low coronary restenosis rates of $0 \%$ to $9 \%$ at six and 12 months (unpublished data, ELUTES, ASPECT, TAXUS I, and SIRIUS trials, 2002)..$^{3-6}$ These impressive results have led some clinicians to speculate that drug eluting stents have remedied the problem of in-stent restenosis.

In this atmosphere of heightened enthusiasm, however, still linger the preclinical animal studies of sirolimus eluting (Carter AJ, 2002; unpublished results) and paclitaxel eluting stents (Heldman AW, 2002; unpublished results), , showing efficacy at one month with lack of benefit by three and six months. The disparate results between six month clinical success and the failure of long term efficacy in animals has generated a scepticism that animal models do not accurately reflect the response to drug eluting coronary stents in humans. ${ }^{8}$ Although this tenet continues to gain momentum, is the complete dismissal of preclinical animal work justified? This fundamental question is essential, as preclinical testing is ingrained in the regulatory approval process traditionally used to determine the safety and potential efficacy or equivalency of treatments for human use. It can be argued that insufficient preclinical testing may have led to the recent failures of actinomycin-D (European Society of Cardiology Congress 2002, unpublished data) and the paclitaxel derivate (QP2 or 7-hexanoyltaxol) eluting polymer stents ${ }^{9}$ in de novo and restenotic lesions. It should be recognised that the vast knowledge of vascular healing and repair derived from animal studies is echoed in today's clinical achievements in the field of stent restenosis.

\section{COMPARISON OF VASCULAR HEALING IN ANIMALS AND HUMANS}

In animals or humans, the local response to a bare stainless steel stent in normal or diseased atherosclerotic coronary arteries follows a distinct pattern of arterial injury and repair accompanied by some degree of neointimal formation and endothelialisation. These healing events, however, can be notably altered with the addition of polymers, antirestenotic drugs, or both. Nevertheless, it is poorly appreciated that neointimal responses are exaggerated and that the time course of healing is more prolonged in humans than in animals. ${ }^{11} \mathrm{~A}$ comparison of arterial healing after coronary stenting in animals and humans is shown in fig 1. In a morphometric analysis of over 40 human stents collected at necropsy, peak neointimal thickness (mean (SD), $0.78(0.37) \mathrm{mm}$ ) occurs between six months and one year, with approximately $22 \%$ regression in neointimal growth after one year. In contrast, neointimal formation in stented pig coronary arteries is maximal at one month $(0.33$ $(0.24) \mathrm{mm})$, with around $25 \%$ lesion regression taking place over the following three to six months. Thus the response to healing after placement of a bare stainless steel stent in a human coronary artery is five to six times longer than in pig or rabbits. This concept is essential for the evaluation of a drug eluting stent: the interval from implantation to the actual data collection becomes crucial to the final outcome of testing. For a better understanding of the differences in the stent healing, a brief review of stent pathology in human coronary arteries and animals is useful to highlight temporal differences in vascular healing.

Abbreviations: ASPECT, Asian paclitaxel eluting stent clinical trial; ELUTES, evaluation of paclitaxel-eluting stent; IVUS, intravascular ultrasound; MACE, major adverse cardiac event; RAVEL, randomised study with the sirolimus eluting velocity balloon expandable stent in treatment of de novo native coronary artery lesions; SIRIUS, sirolimus eluting stent 

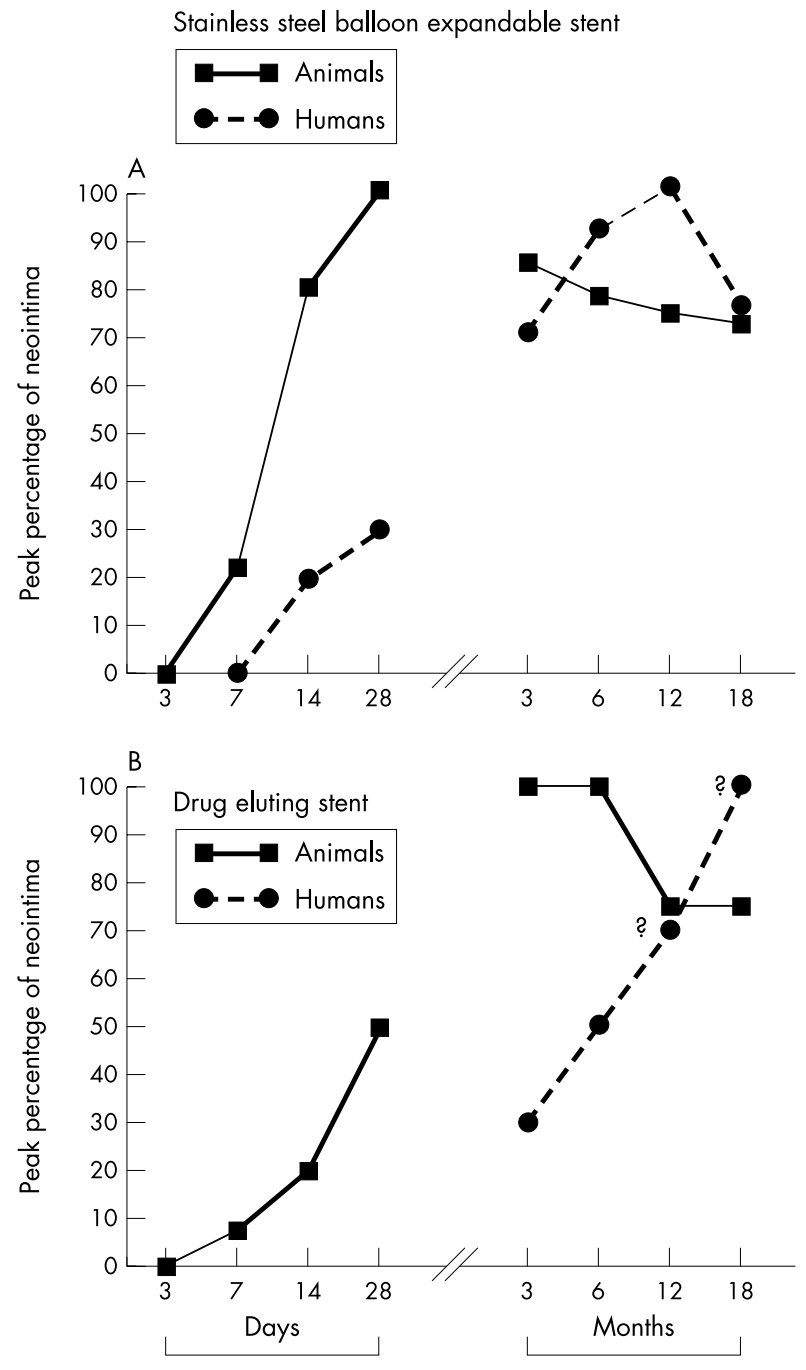

Time after stent implantation

Figure 1 Line plot showing the temporal relation of peak neointimal growth in animals and humans following the placement of either "bare" stainless steel (A) or a drug eluting sirolimus or paclitaxel stent (B). The plots are predominantly derived from morphometric analysis of pig and human coronary stents; the drug eluting stent data in humans are projected from angiographic results. ${ }^{5}$ In animals, peak neointimal growth in stainless steel stents is observed at 28 days, compared with 6-12 months in humans. In human coronary arteries with drug eluting stents, the precise time course of peak neointimal growth is unknown (?). Animal studies of drug eluting stents, however, show favourable results at 28 days, with a lack of sustained efficacy at 3 and 9 months. The generalised delayed healing with drug eluting stents is thought to occur secondarily from an inhibition of smooth muscle cell proliferation and migration, and/or from the suppression of inflammation.

\section{STENT HEALING}

\section{Animal models}

The results of animal model studies are illustrated in figs $l$ and 2. Although most tests of stent efficacy are performed at 28 days, there are a surprisingly few long term morphological studies on restenosis in pig coronary arteries. ${ }^{12}{ }^{13}$ The early (one to three days) morphological response to stenting predominantly consists of platelet/fibrin deposition surrounding struts and scattered neutrophils within adherent luminal thrombi. By day 7, organising mural thrombi extending between stent struts contain smooth muscle cells and macrophages with scattered lymphocytes, red cells, and luminal endothelial cells. At 14 days, fibrin is still present with a few chronic inflammatory cells remaining around stent struts. At this stage, the neointima contains few smooth muscle cells within a proteoglycan-rich matrix. By 28 days, the neointima contains a larger number of smooth muscle cells, proteoglycans, and type III collagen, with rare macrophages and giant cells around stent struts; fibrin is usually absent. The rate of neointimal expansion is greatest between 7-14 days, with maximal thickness achieved at one month. Over the next three to six months, the extracellular matrix becomes enriched in collagen type I, with neointimal shrinkage and remodelling. Cell proliferation in the neointima peaks at seven days, is reduced by approximately half at 14 days, and returns to a low baseline level by one month. Of note, stented rabbit iliac arteries follow a time course of healing similar to pig coronary arteries.

\section{Human studies}

The results of human studies are illustrated in figs 1 and 3 In stented human coronary arteries, platelet and fibrin deposition persists up to 14 and 30 days, respectively. ${ }^{10}$ Inflammatory cells, consisting of polymorphonuclear leucocytes and macrophages, are present by one to three days, and macrophages persist for at least three months. T lymphocytes appear at two to three weeks and persist beyond six months. Collections of smooth muscle cells-the main cellular component of the restenotic lesion-are evident by 14 days following stenting. The extracellular matrix, composed initially of proteoglycans and type III collagen, is gradually replaced by type I collagen past 12 months. The time course of intimal smooth muscle cell proliferation in relation to in-stent restenosis in humans is not known. Cell proliferation studies in human restenotic coronary atherectomy tissue retrieved from a few days to just beyond one year have thus far generally shown a low proliferation index without the characteristic peak found in existing animal models of angioplasty and stenting. ${ }^{14}$ Clearly, significantly more rapid proliferative events appear to occur in animals as distinct from human restenotic coronary arteries. Furthermore, rather than a simple proliferative response, smooth muscle cell migration from within the plaque or media to the expanding neointima may be the more dominant factor contributing to in-stent restenosis in humans.

\section{TEMPORAL DIFFERENCES IN ARTERIAL HEALING IN HUMANS AND ANIMALS}

One obvious explanation for the delayed arterial healing in humans is the underlying atherosclerotic process, which usually manifests in the fifth to sixth decade of life. Arterial interventions in animals are usually performed in young adults, and stents are typically placed in apposition to a normal smooth muscle-rich medial wall without inflammation. The absence of atherosclerotic disease is likely to contribute to a more predictable healing response in animals. In contrast, in diseased human coronary arteries, at least $70 \%$ of the stent is in direct contact with the underlying atherosclerotic plaque. ${ }^{10}{ }^{11}$ The physical components of the lesion relative to the position of the stent probably affect the local response to healing. For example, stent struts in proximity to a necrotic core are exposed to few smooth muscle cells and thus heal slower than stents in direct contact with areas of adaptive intimal thickening, which contain an abundance of smooth muscle cells. ${ }^{10}$ Similarly, stents overlying calcified and densely fibrotic plaques also take longer to develop a neointima, as these plaques are also relatively hypocellular and must recruit smooth muscle cells from other remote areas of the arterial wall to cover bare struts.

The differential rate of healing between animals and humans may also be proportional to the longevity of the species. The typical life span of a human is more than 70 years; in contrast, pigs have a life span of 16 years, and rabbits 5-6 years. The age dependent biological differences in healing rates are exemplified in animal models of cutaneous wounds. 

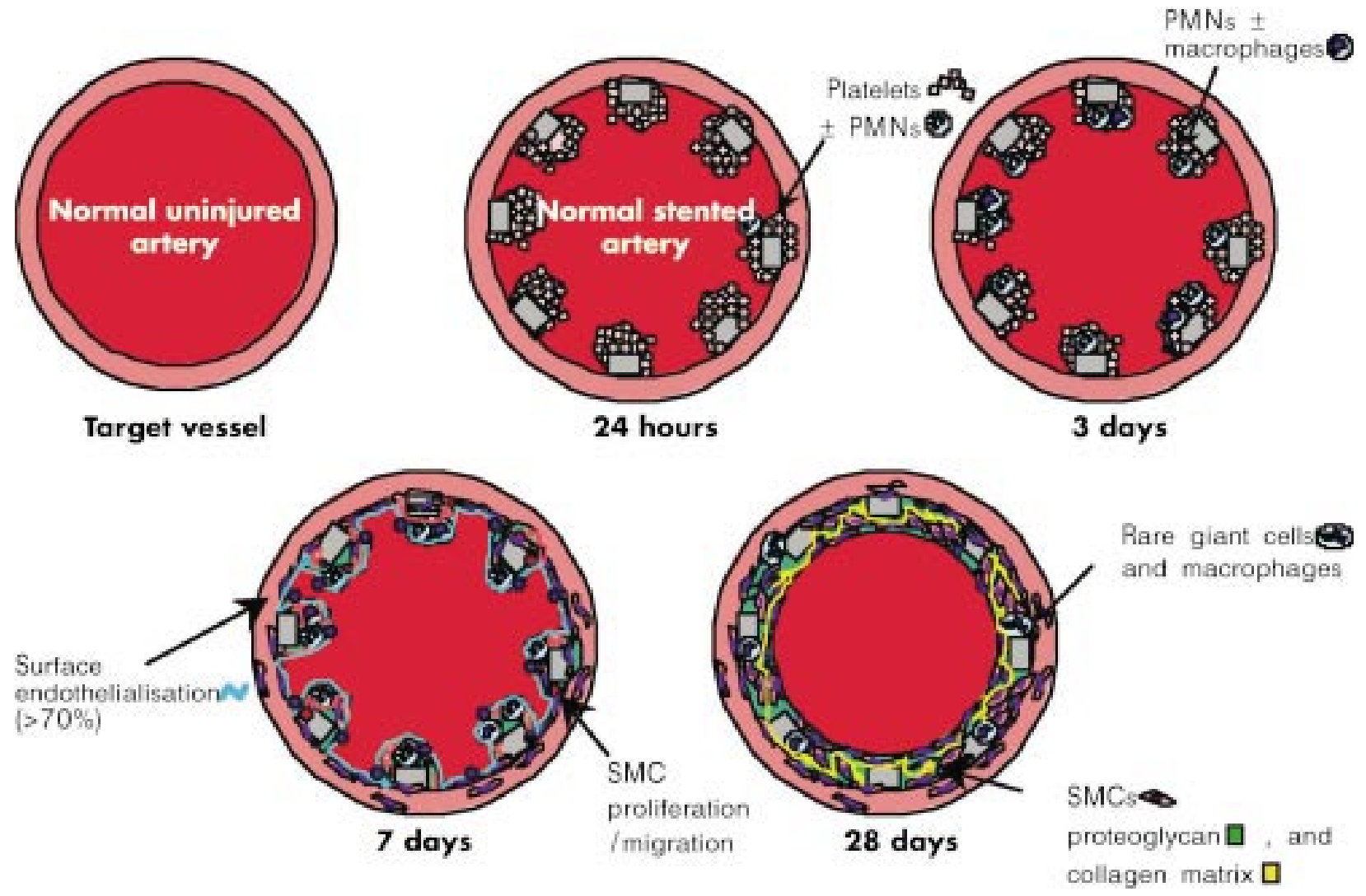

Figure 2 Illustration of the vascular response to a balloon expandable stainless steel stent implanted in a normal pig coronary or rabbit iliac artery. PMNs, polymorphonuclear leucocytes; SMCs, smooth muscle cells.

This analogy may be appropriate to in-stent restenosis, as the developing neointima is similarly considered to be a response to traumatic injury. In the pig, the extent of cutaneous re-epithelialisation declines with age, partly because of a decrease in the expression of growth factors. ${ }^{15}$ Further, wound contraction "remodelling" is accelerated in juvenile pigs. The type of injury is another consideration; wound healing is delayed in traumatic compared with surgically induced injury, and if the injury site is large. ${ }^{16}{ }^{17}$ Human coronary stenting is often associated with extensive local trauma characterised by plaque splitting and medial disruption. Conversely, most stents in animals are deployed in normal arteries with 1:1.1 stent to artery ratio, resulting in only mild arterial injury. ${ }^{18}$

\section{LESSONS LEARNED FROM BRACHYTHERAPY}

Brachytherapy in animal models - catheter ( $\beta$ or $\gamma$ radiation) or stent ( $\beta$ radiation) based-inhibits neointimal formation, with evidence of incomplete healing at one to three months. ${ }^{19-21}$ Continued healing, however, is accompanied by neointimal growth, and six month brachytherapy studies in animals fail to show a benefit. For example, Coussement and colleagues, using ${ }^{186} \mathrm{Re} \beta$ radiation (20 Gy dose) delivered through a balloon at six months in pig balloon injured coronary arteries, showed a significant decrease in lumen size with a reciprocally greater neointimal area than control non-radiated balloon injured arteries. ${ }^{21}$ Persistent fibrin deposition within the neointima was a notable finding in the radiated arteries. Complete endothelialisation was absent, a potential mechanism of late subacute thrombosis in animals and humans. ${ }^{21-24}$

The lack of sustained efficacy after brachytherapy in animals stands in direct contrast to early clinical trials, in which reduced arterial stenosis was evident at six months. A likely explanation is that healing occurs more rapidly in normal animal arteries because eventually there is a progressive arterial stenosis between six months and three years, as reported in patients receiving brachytherapy. ${ }^{8}$ The longest term human coronary brachytherapy data available (five years) show a mean (SD) arterial stenosis of 50.5 (22.9)\% (range 19.4-100\%) accompanied by positive remodelling, excessive adventitial fibrosis, and intimal calcification (Waksman R, 2001; unpublished data). Lumen loss and neointimal growth are more dramatic in radioactive stents analysed between six months and one year. ${ }^{25}$ Taken together, these findings lend strong supportive evidence of late lumen loss in radiated arteries in humans and closely parallel the negative results in animal studies. The pathology of delayed healing with radiation is not unlike that of drug eluting stents showing persistent intimal fibrin deposition, inflammation, a paucity of smooth muscle cells in a proteoglycan-rich matrix, and incomplete endothelialisation. The similarity in histology raises the possibility that, like brachytherapy, neointimal growth with drug eluting stents will be only delayed rather than prevented.

\section{HOW DO WE INTERPRET THE RESULTS OF DRUG ELUTING STENTS IN ANIMALS?}

Sirolimus eluting or paclitaxel eluting stents at one month in pig and rabbit arteries show delayed healing, characterised by persistent fibrin deposition, variable inflammation, and incomplete endothelialisation. Those drugs that cause medial necrosis and positive remodelling (for example, actinomycin-D or paclitaxel) may induce exuberant neointimal formation at sites adjacent to the normal arterial wall (Virmani R, 2002; unpublished observations). The histological findings of drug eluting stents at one month in pig coronary 

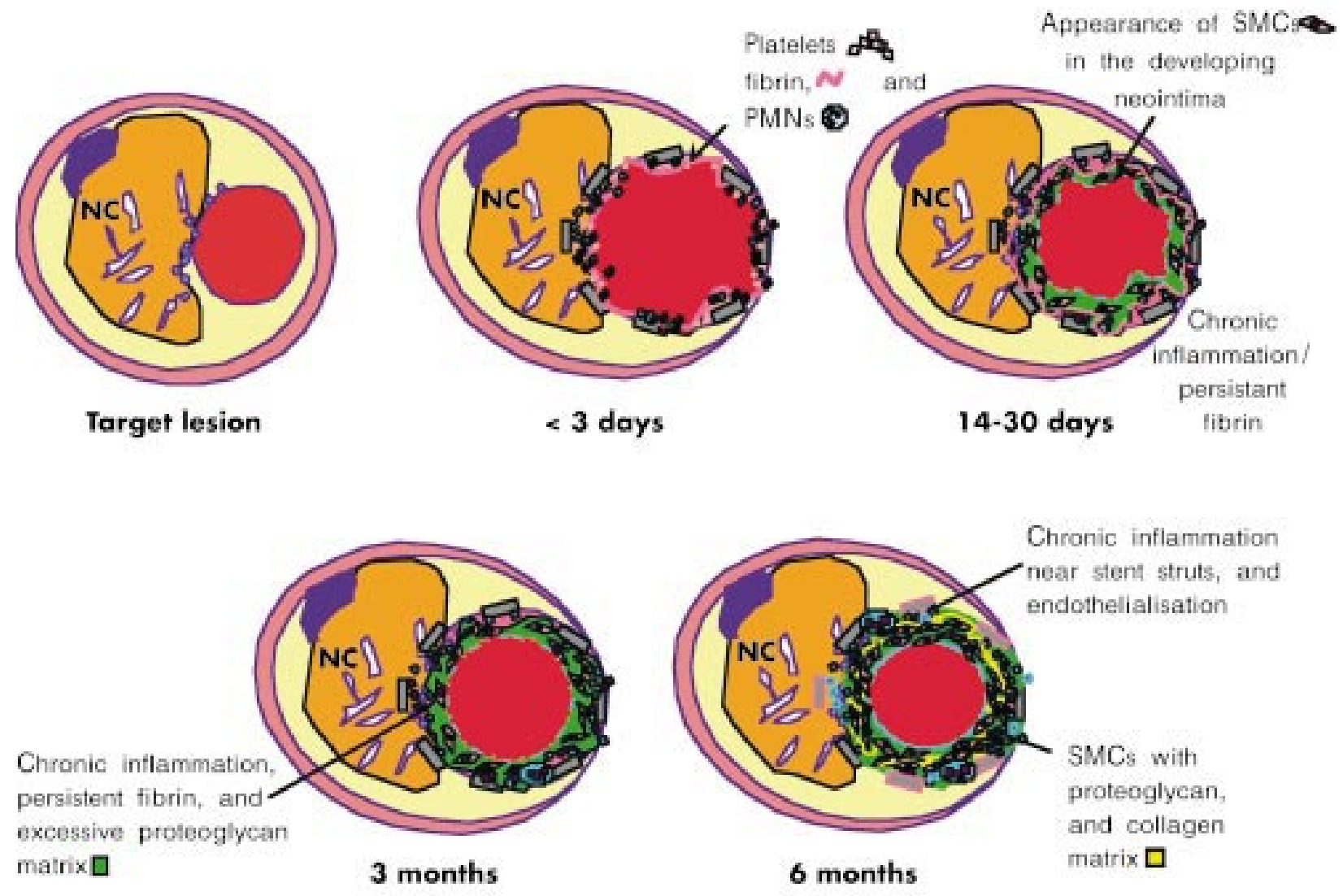

Figure 3 Illustration of the vascular response to a balloon expandable stainless steel stent implanted in an atherosclerotic human coronary artery. NC, necrotic core; PMNs, polymorphonuclear leucocytes; SMCs, smooth muscle cells.

arteries are similar to those of "bare" stainless steel stent arteries seven and 14 days, thus representing a two to three week delay in healing. Late studies at 90 or 180 days with either paclitaxel coated (pig and rabbit) or sirolimus (pig) coated stents have been negative. At this time, neointimal healing is relatively complete; fibrin and inflammation are absent, and the luminal surface is fully endothelialised. Notably, elution profiles of sirolimus eluting stents in pig coronary arteries show that $63 \%$ of the initial dose (196 (9) $\mu \mathrm{g} / \mathrm{stent}$ ) is eluted by 14 days; at this time, arterial wall concentrations are at maximum (around $160 \mu \mathrm{g}$ ) and are reduced by $50 \%$ by 28 days. ${ }^{26}$ The loss of sustained efficacy may simply be an effect of an insignificant amount of drug on the stent. Alternatively, persistent fibrin deposition within the first one to two months may lead to the formation of fibrin split products which act as a stimulus for smooth muscle cell proliferation. ${ }^{27}$

\section{CLINICAL STUDIES WITH DRUG ELUTING STENTS: A COMPARISON WITH ANIMAL MODELS}

In the initial clinical study of sirolimus coated BX Velocity stents in 30 patients with fast release $(<15$ days $)$ or slow release $(\geqslant 28$ days) implants, there was minimal neointimal hyperplasia at four months detected by ultrasound and quantitative angiography. ${ }^{3}$ No major adverse cardiac events (MACE) defined as stent thrombosis, repeat revascularisation, myocardial infarction, or death-occurred up to eight months. In the larger multicentre, randomised, double blind RAVEL trial (randomised study with the sirolimus eluting velocity balloon expandable stent in the treatment of patients with de novo native coronary artery lesions) comparing sirolimus eluting with standard uncoated stents in 232 patients, restenosis rates at 210 days in the sirolimus and control stent groups were $0 \%$ and $26 \%$, respectively. ${ }^{5}$ The event-free survival with sirolimus eluting stents was $94.1 \%$ and $70.9 \%$ in control group; however, only $50 \%$ of patients with document restenosis in the control group were symptomatic.

A subsequent US multicentre trail, SIRIUS (sirolimus eluting stent), was established to test the efficacy of sirolimus eluting Bx Velocity stents in more complex lesion morphologies (Leon MB, 2002; unpublished data). A preliminary analysis of 400 patients at eight months showed an in-stent restenosis rate of $2.0 \%$ and $31.1 \%$ with sirolimus eluting and uncoated control stents, respectively. The peri-stent restenosis rates ( $5 \mathrm{~mm}$ proximal and distal outside margins of the stent), however, were similar in the two groups; thus in-segment restenosis (within both margins and stent) reached a maximum of $9 \%$ and $32 \%$ in sirolimus and uncoated stents. At nine months, MACE rates were significantly less in sirolimus eluting stents $(8.9 \%)$ than in controls $(18.9 \%)$, with notable reductions in target vessel revascularisation of $4.7 \%$ and $16.7 \%$, respectively. Thus a $0 \%$ restenosis rate with sirolimus eluting Bx Velocity stents is unlikely, as these devices are used in more complex and challenging coronary lesions. Further, the failure to suppress neointimal hyperplasia at the stent margins with sirolimus may become a critical issue, particularly in smaller vessels.

Intravascular ultrasound (IVUS) findings in a subset of 95 patients from the RAVEL trial showed an equally remarkable reduction in neointimal hyperplasia $\left(2 \quad(5) \mathrm{mm}^{3} \quad v 37\right.$ (28) $\mathrm{mm}^{3}$ ) and per cent stent volume obstructed ( 1 (3)\% v 29 $(20) \%)$ in sirolimus and control stents, respectively, at six months. ${ }^{6}$ It is important to emphasise, however, that the negligible increase in neointimal growth with sirolimus stents suggest that many of the struts remain uncovered as a result 
of incomplete healing, which raises doubts as to whether restenosis was truly prevented rather than just delayed. In addition, patients receiving sirolimus eluting stents showed a significant $21 \%$ incidence of malapposition of the stent to the arterial wall, compared with only $4 \%$ in controls. This finding may represent positive remodelling of the vessel with accumulated thrombus between the stent struts and vessel wall, which would not be visualised by IVUS. Careful long term follow up by IVUS is necessary to clarify the significance and aetiology of malapposition with sirolimus eluting stents.

Extremely low rates of restenosis $(0-5 \%)$ at six and 12 months have similarly been observed for paclitaxel eluting stents, compared with $11-27 \%$ in control patients (unpublished results, 2002: TAXUS I (feasibility study evaluating safety of the NIRx paclitaxel coated conformer coronary stent for the treatment of de novo coronary lesions) and ASPECT (Asian paclitaxel eluting stent clinical trial)). MACE rates were $0 \%$ in the paclitaxel eluting stent group versus $\geqslant 7 \%$ in controls. As with sirolimus, the extent of healing of the intimal surface overlying paclitaxel eluting stents in humans is unknown. A recent study, however, of 15 patients treated for in-stent restenosis with QuaDS stents (Quanam Medical Corporation) containing the paclitaxel derivative 7-hexanoyltaxol (QP2 or "taxen") may provide some insight into stent healing in humans. ${ }^{28}$ Although at six months there was minimal in-stent intimal hyperplasia (late loss, $0.47(1.01) \mathrm{mm}$ ), at 12 months there was an aggressive increase in neointimal growth (late loss, $1.36(0.94) \mathrm{mm}$ ), resulting in a dramatic $61.5 \%$ rate of restenosis. Morphological examination of atherectomy tissue from a subset of these patients showed persistent fibrin admixed with smooth muscle cells and extensive proteoglycan matrix, thus demonstrating incomplete neointimal healing even at 12 months (Virmani R, 2002; unpublished data).

At the very least, the data from the QuaDS-QP2 stent emphasise the fact that late neointimal regrowth cannot be ruled out a priori with any drug eluting stent. Further, these histological results of restenotic tissue from QuaDS-QP2 stents are strikingly similar to those in animal models with paclitaxel eluting stents, even though the time course of healing is more prolonged in humans. Finally, the results of the QuaDS-QP2 stents and the terminated trial of actinomycin D eluting stents indicate that antiproliferative and antiinflammatory drugs will not all uniformly show a drug class effect for the successful prevention of in-stent restenosis.

\section{CONCLUSIONS}

Animal models of stenting probably predict human responses, as the stages of healing are remarkably similar. What is characteristically different is the temporal response to healing, which is substantially prolonged in humans. We therefore postulate that the prevention of restenosis in recent clinical trials of drug eluting stents represents a near absent or incomplete phase of intimal healing. To this point, the negative findings of drug eluting stents in 90 and 180 day animal studies-at a time when healing is complete-may correspond to a reasonable approximation of two to three years in humans. Continued long term follow up of patients with drug eluting stents for MACE and angiographic restenosis is therefore imperative. At best, drug eluting stents may have solved the in-stent restenosis problem; at worse, they may lead to adverse long term late thrombosis and restenosis. An intermediate result would be delayed restenosis, which would improve the interim quality of life and provide time for the development of novel treatments aimed at sustained neointimal suppression. It is extremely important to emphasise, however, that the recent clinical success of drug eluting stents should not create unfounded prejudices against animal models. Although they do not exactly simulate human in-stent restenosis, they are essential for the assessment of efficacy and safety of interventional devices and provide useful information on the pathology of arterial healing responses to antirestenotic drugs.

\section{ACKNOWLEDGEMENTS}

The opinions or assertions contained herein are the private views of the authors and are not to be construed as official or as reflecting the views of the US Department of the Army or the US Department of Defense.

\section{Authors' affiliations}

R Virmani, F D Kolodgie, A Farb, Department of Cardiovascular Pathology, Armed Forces Institute of Pathology, Washington DC, USA A Lafont, Hôpital Européen Georges Pompidou, INSERM EO0-16, Université, Paris V, France

\section{REFERENCES}

1 American Heart Association. 2002 Heart and stroke statistical update. Dallas: AHA, 2001

2 Smith SC, Dove JT, Jacobs AK, et al. ACC/AHA guidelines of percutaneous coronary interventions (revision of the 1993 PTCA guidelines) - executive summary. A report of the American College of Cardiology/American Heart Association task force on practice guidelines (committee to revise the 1993 guidelines for percutaneous transluminal coronary angioplasty). J Am Coll Cardiol 2001;37:2215-39.

3 Sousa JE, Costa MA, Abizaid A, et al. Lack of neointimal proliferation after implantation of sirolimus-coated stents in human coronary arteries: a quantitative coronary angiography and three-dimensional intravascular ultrasound study. Circulation 2001;103:192-5.

4 Sousa JE, Costa MA, Abizaid AC, et al. Sustained suppression of neointimal proliferation by sirolimus-eluting stents: one-year angiographic and intravascular ultrasound follow-up. Circulation 2001;104:2007-11.

5 Morice MC, Serruys PW, Sousa JE, et al. A randomized comparison of a sirolimus-eluting stent with a standard stent for coronary revascularization. N Engl J Med 2002;346:1773-80.

6 Serruys PW, Degertekin M, Tanabe K, et al. Intravascular ultrasound findings in the multicenter, randomized, double-blind RAVEL (RAndomized study with the sirolimus-eluting VElocity balloon-expandable stent in the treatment of patients with de novo native coronary artery Lesions) trial. Circulation 2002;106:798-803.

7 Farb A, Heller PF, Shroff S, et al. Pathological analysis of local delivery of paclitaxel via a polymer-coated stent. Circulation 2001;104:473-9.

8 Teirstein PS. Living the dream of no restenosis. Circulation 2001;104:1996-8.

9 Liistro F, Colombo A. Late acute thrombosis after paclitaxel eluting stent implantation. Heart $2001 ; 86: 262-4$

10 Farb A, Sangiorgi G, Carter AJ, et al. Pathology of acute and chronic coronary stenting in humans. Circulation 1999;99:44-52.

11 Farb A, Weber DK, Kolodgie FD, et al. Morphological predictors of restenosis after coronary stenting in humans. Circulation 2002; 105:2974-80.

12 Carter AJ, Laird JR, Farb A, et al. Morphologic characteristics of lesion formation and time course of smooth muscle cell proliferation in a porcin proliferative restenosis model. J Am Coll Cardiol 1994;24:1398-405.

13 Taylor AJ, Gorman PD, Kenwood B, et al. A comparison of four stent designs on arterial injury, cellular proliferation, neointima formation, and arterial dimensions in an experimental porcine model. Cathet Cardiovasc Intervent 2001;53:420-5

14 O'Brien ER, Alpers CE, Stewart DK, et al. Proliferation in primary and restenotic coronary atherectomy tissue. Implications for antiproliferative therapy. Circ Res 1993;73:223-31.

15 Yao F, Visovatti S, Johnson CS, et al. Age and growth factors in porcine full-thickness wound healing. Wound Repair Regen 2001;9:371-7.

16 Forrester JS, Fishbein M, Helfant R, et al. A paradigm for restenosis based on cell biology: clues for the development of new preventive therapies. J Am Coll Cardiol 1991;17:758-69.

17 Schwartz RS, Huber KC, Murphy JG, et al. Restenosis and the proportional neointimal response to coronary artery injury: results in a porcine model. J Am Coll Cardiol 1992:19:267-74.

18 Carter AJ, Laird JR, Kufs WM, et al. Coronary stenting with a novel stainless steel balloon-expandable stent: determinants of neointimal formation and changes in arterial geometry after placement in an atherosclerotic model. J Am Coll Cardiol 1996;27:1270-7.

19 Carter AJ, Scott D, Bailey L, et al. Dose-response effects of ${ }^{32} \mathrm{P}$ radioactive stents in an atherosclerotic porcine coronary model. Circulation 1999; 100:1548-54

20 Farb A, Shroff S, John M, et al. Late arterial responses (6 and 12 months) after (32)P beta-emitting stent placement: sustained intimal suppression with incomplete healing. Circulation 2001;103:1912-19.

21 Coussement PK, Stella P, Vanbilloen H, et al. Intracoronary beta-radiation of de novo coronary lesions using a (186)Re liquid-filled balloon system: six-month results from a clinical feasibility study. Cathe Cardiovasc Intervent 2002;55:28-36.

22 Costa MA, Sabat M, van der Giessen WJ, et al. Late coronary occlusion after intracoronary brachytherapy. Circulation 1999;100:789-92. 
23 Waksman R, Bhargava B, Mintz GS, et al. Late total occlusion after intracoronary brachytherapy for patients with in-stent restenosis. J Am Coll Cardiol 2000;36:65-8

24 Kaluza GL, Raizner AE, Mazur W, et al. Long-term effects of intracoronary beta-radiation in balloon- and stent-injured porcine coronary arteries. Circulation 2001;103:2108-13.

25 Kay IP, Wardeh AV, Kozuma K, et al. Radioactive stents delay but do not prevent in-stent neointimal hyperplasia. Circulation 2001;103 14-17.
26 Klugherz BD, Llanos $G$, Lieuallen W, et al. Twenty-eight-day efficacy and phamacokinetics of the sirolimus-eluting stent. Coron Artery Dis and phamacokine

27 Naito M, Stirk CM, Smith EB, et al. Smooth muscle cell outgrowth stimulated by fibrin degradation products. The potential role of fibrin fragment $E$ in restenosis and atherogenesis. Thromb Res 2000;98:165-74.

28 Liistro F, Stankovic G, Di Mario C, et al. First clinical experience with a paclitaxel derivate-eluting polymer stent system implantation for in-stent restenosis: immediate and long-term clinical and angiographic outcome. restenosis: immediate and long-
Circulation 2002;105:1883-6.

\section{IMAGES IN CARDIOLOGY}

\section{Huge mass bordering on left atrium raises coronary artery}

A

45 year old carpenter with an abnormal chest radiograph was referred to us. Computed tomographic (CT) chest scan showed round mass, $7.5 \mathrm{~cm}$ in diameter, bordering on the left atrium with patchy calcification around it. Density inside was almost homogeneous and no effect of the enhancement was observed. Three dimensional reconstruction from the CT showed that the left circumflex artery was raised by the mass and its proximal side dilated (lower panels, left and centre). Coronary angiography did not detect any feeding artery to the mass, and laboratory tests including tumour makers showed no abnormality. The mass was surgically enucleated.
Histological study revealed the mass to be an encapsulated pseudocyst beneath the pericardium and contained the old thrombus (lower panel, right). The precise mechanism of this thrombus formation was unknown, but might be related to blunt trauma received during the patient's work.

H Okamura

K Bando

M Higashi o-hideo@d9.dion.ne.jp
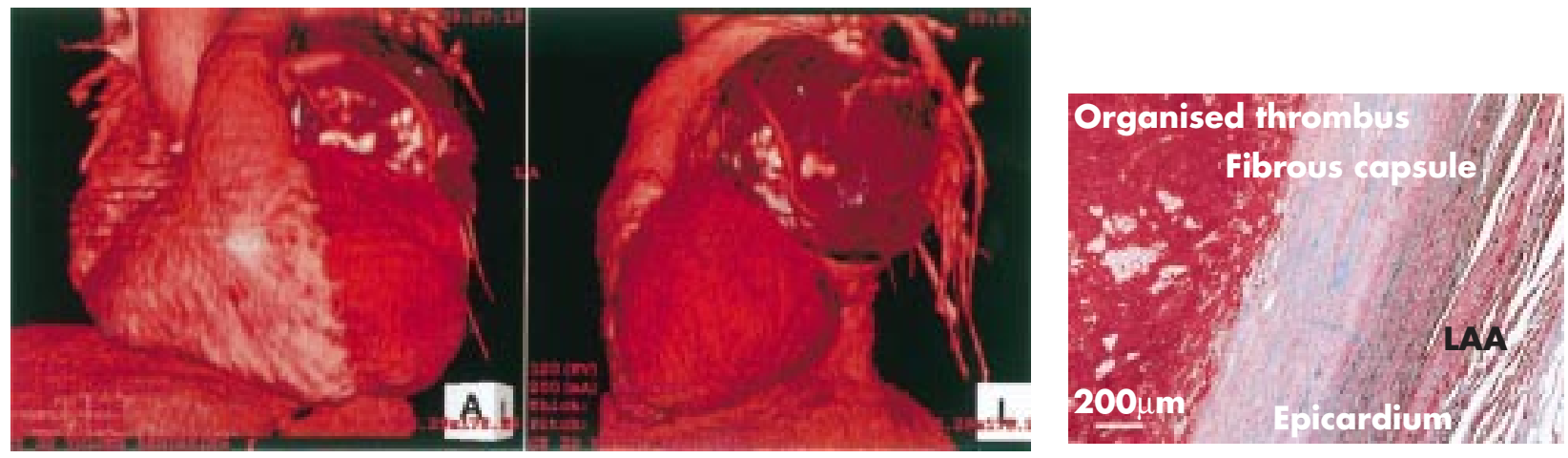

\section{Acute left ventricular rupture after myocardial infarction}

$A^{3}$

71 year old woman with a two hour history of chest pain and ST segment elevation in leads V1-V4 was admitted to our hospital with the diagnosis of acute myocardial infarction and treated with tissue plasminogen activator. Forty eight hours after admission, the patient presented sudden transient hypotension without other symptoms. Transthoracic echocardiography, performed immediately after the onset of hypotension, showed a small amount of pericardial effusion. Left ventricular angiography showed a digital false aneurysm

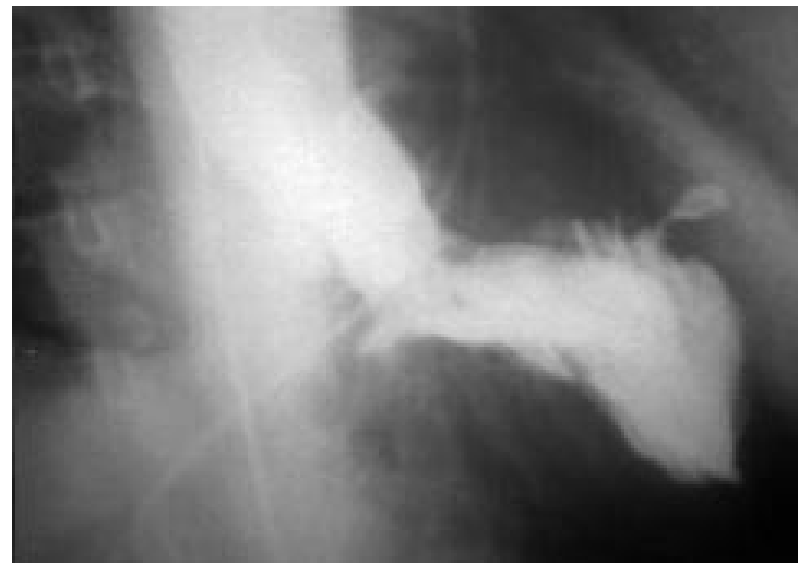

(below left) in the left anterior ventricular wall. In the operating room $200 \mathrm{ml}$ of haemopericardial effusion were evacuated and left ventricular rupture was confirmed. The patient underwent simple patch covering of the wall rupture (below right) and left anterior descending artery bypass grafting. The patient returned to normal activity.

P L Sanchez pedroymiriam@usuarios.retecal.es

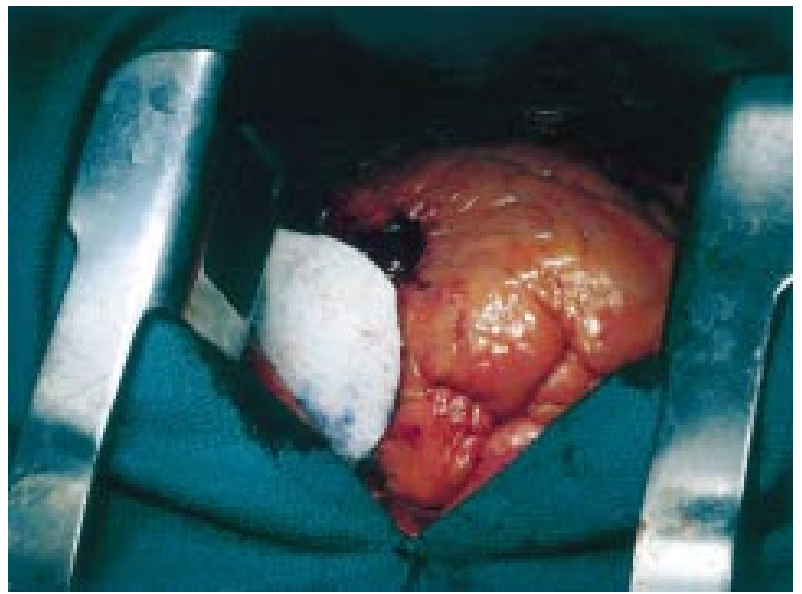

